\title{
Capecitabine and stereotactic radiation in the management of breast cancer brain metastases
}

\author{
Matthew N. Mills', Afrin Naz², Chetna Thawani², Chelsea Walker², Nicholas B. Figura', Sergiy Kushchayev³, \\ Daniel E. Oliver ${ }^{1}$, Arnold B. Etame ${ }^{4}$, Hsiang-Hsuan Michael Yu', Timothy J. Robinson', James K. C. Liư', \\ Michael A. Vogelbaum ${ }^{4}$, Peter A. Forsyth ${ }^{4}$, Brian J. Czerniecki ${ }^{5}$, Hatem H. Soliman ${ }^{5}$, Hyo S. Han ${ }^{5}$ and \\ Kamran A. Ahmed ${ }^{1 *}$
}

\begin{abstract}
Background: Little is known about the safety and efficacy of concurrent capecitabine and stereotactic radiotherapy in the setting of breast cancer brain metastases (BCBM).

Methods: Twenty-three patients with BCBM underwent 31 stereotactic sessions to 90 lesions from 2005 to 2019 with receipt of capecitabine. The Kaplan-Meier method was used to calculate overall survival (OS), local control (LC), and distant intracranial control (DIC) from the date of stereotactic radiation. Imaging was independently reviewed by a neuro-radiologist.

Results: Median follow-up from stereotactic radiation was 9.2 months. Receptor types of patients treated included triple negative $(n=7)$, hormone receptor $(\operatorname{HR})+/$ HER2- $(n=7)$, HR+/HER2 $+(n=6)$, and HR-/HER2+ $(n=3)$. Fourteen patients had stage IV disease prior to BCBM diagnosis. The median number of brain metastases treated per patient was 3 (1 to 12). The median dose of stereotactic radiosurgery (SRS) was $21 \mathrm{~Gy}$ (range: 15-24 Gy) treated in a single fraction and for lesions treated with fractionated stereotactic radiation therapy (FSRT) 25 Gy (24-30 Gy) in a median of 5 fractions (range: $3-5$ ). Of the 31 stereotactic sessions, 71\% occurred within 1 month of capecitabine. No increased toxicity was noted in our series with no cases of radionecrosis. The 1-year OS, LC, and DIC were 46, 88, and $30 \%$, respectively.
\end{abstract}

Conclusions: In our single institution experience, we demonstrate stereotactic radiation and capecitabine to be a safe treatment for patients with BCBM with adequate LC. Further study is needed to determine the potential synergy between stereotactic radiation and capecitabine in the management of BCBM.

Keywords: Capecitabine, Xeloda, Breast cancer, Brain metastases, Stereotactic radiotherapy

\footnotetext{
* Correspondence: Kamran.Ahmed@moffitt.org

${ }^{1}$ Department of Radiation Oncology, H. Lee Moffitt Cancer Center and

Research Institute, 12902 Magnolia Dr, Tampa, FL 33612, USA

Full list of author information is available at the end of the article
}

(c) The Author(s). 2021 Open Access This article is licensed under a Creative Commons Attribution 4.0 International License, which permits use, sharing, adaptation, distribution and reproduction in any medium or format, as long as you give appropriate credit to the original author(s) and the source, provide a link to the Creative Commons licence, and indicate if changes were made. The images or other third party material in this article are included in the article's Creative Commons licence, unless indicated otherwise in a credit line to the material. If material is not included in the article's Creative Commons licence and your intended use is not permitted by statutory regulation or exceeds the permitted use, you will need to obtain permission directly from the copyright holder. To view a copy of this licence, visit http://creativecommons.org/licenses/by/4.0/. The Creative Commons Public Domain Dedication waiver (http://creativecommons.org/publicdomain/zero/1.0/) applies to the data made available in this article, unless otherwise stated in a credit line to the data. 


\section{Background}

Breast cancer brain metastases (BCBM) have become an increasingly common diagnosis in advanced breast cancer [1]. Triple negative and HER2+ breast cancers have been identified as risk factors for the development of brain metastases [2-4]. Local therapies including surgical resection and radiation therapy continue to be mainstays in the management of brain metastases.

Given the concurrent extracranial disease burden in brain metastatic patients, systemic therapies are often advised which may also have an impact on intracranial brain control [1]. Capecitabine is an oral prodrug of 5flourouracil (5-FU), an antimetabolite, and undergoes 3step enzymatic conversion to 5-FU. While capecitabine does not cross the intact blood-brain-barrier (BBB), it has demonstrated intracranial penetration in surgically resected $B C B M$ samples, presumably due to the defective $\mathrm{BBB}$ that is associated with contrast enhancement [5]. In the management of HER2+ BCBM, capecitabine has been combined with the HER tyrosine kinase inhibitor (TKI) lapatinib demonstrating a central nervous system (CNS) response rate of 66\% [6]. The HER TKI neratinib demonstrated activity against HER2-positive BCBM with an objective response rate of $49 \%$ in lapatinib naive patients [7]. Capecitabine alone is commonly prescribed in the adjuvant setting in triple negative tumors following results of the CREATE-X trial which demonstrated the rate of disease-free survival as $69.8 \%$ in the capecitabine group versus $56.1 \%$ in the control group and improved overall survival (OS) [8].

Capecitabine and 5-FU are known radiosensitizers and are commonly used alongside radiation therapy to enhance the effect of therapy. This is commonly the case in gastrointestinal malignancies such as rectal, pancreatic, and anal cancers [9-11]. Care must be taken to avoid the late effects of radiation therapy in the management of brain metastases with the most worrisome side effect being radionecrosis [12]. Given the known effects of capecitabine as a radiosensitizer, its known role in the management of BCBM, and its increasingly common use in the systemic management of triple negative breast cancer, we conducted a retrospective analysis to assess adverse events of combined therapy as well as potential for a synergistic effect with concurrent treatment.

\section{Methods}

BCBM patients were identified from our prospectively maintained database of patients receiving radiation therapy. Patients were included if they were diagnosed with brain metastases that were treated with stereotactic radiation within 6 months of receiving capecitabine (either before, during or after administration). Patients underwent stereotactic radiosurgery (SRS) or fractionated stereotactic radiotherapy (FSRT) between January
2005 and November 2019 and were followed until February 2020. The study was approved by the University of South Florida Institutional Review Board. All methods were carried out in accordance with relevant guidelines and regulations.

\section{Stereotactic radiation technique}

Stereotactic radiation technique was conducted as previously described $[13,14]$. Brain metastases were assessed using magnetic resonance imaging (MRI) (Siemens Sonata, Siemens Medical Systems, Erlangen, Germany) with $1 \mathrm{~mm}$ slices for treatment planning purposes prior to the delivery of radiation. The MRI image was coregistered and fused with computed tomography simulation (CT) imaging (General Electric Medical System, Milwaukee, WI). Patient immobilization was achieved by using a commercially available head mask fixation system (BrainlabAG, Feldkirchen, Germany). A uniform 1-2 mm expansion of the gross tumor volume (GTV) was used to create the planning target volume (PTV). All BCBMs were treated with SRS in a single session except 10 metastases treated with FSRT. Seven lesions (8\%) underwent prior surgery. Doses were prescribed to ensure coverage of at least $95 \%$ of the PTV with the prescription dose. Treatments were delivered using multiple dynamic conformal arcs or intensity modulated radiotherapy (IMRT). Image guidance was provided with the BrainLab ExacTrac positioning system.

\section{Follow-up}

Patients in this study were followed with examinations by the treating radiation oncologist, neurosurgeon, and/ or medical oncologist and with MRI imaging at 2-3month intervals [13]. At each visit neurologic status was assessed. Local brain metastasis failure was defined by RANO-BM criteria [15] that remained consistent or demonstrated continued progression on subsequent imaging whereas local brain metastases control (LC) included all treated lesions not meeting this definition. Distant brain metastases failure was defined as new brain metastases or leptomeningeal enhancement outside the previously irradiated field. Distant intracranial control (DIC) was defined as freedom from development of brain metastases or leptomeningeal disease outside of the irradiated field. Imaging was independently reviewed by a neuro-radiologist (SK). OS was calculated from the date of stereotactic radiation and the date of BCBM diagnosis to the date of death.

\section{Statistical analysis}

Statistical analyses were performed using JMP 13 (SAS Institute Inc., Cary, NC, USA). Descriptive statistics were used to summarize the cohort including median and range for continuous variables or counts and percentages 
for categorical variables. The local and DIC rates, as well as OS were calculated from the date of BCBM diagnosis or radiation treatment to the date of progression or death using the Kaplan-Meier (KM) method, with the log-rank test used to test differences between groups.

\section{Results}

\section{Patient and treatment characteristics}

Patient and treatment characteristics are described in Table 1. A total of 23 patients treated over 31 treatments sessions to $90 \mathrm{BCBM}$ lesions were identified. The majority of patients had invasive ductal carcinoma $(n=$ 21; 91\%) with 1 patient with invasive lobular carcinoma, and 1 patient with metaplastic carcinoma (each $4 \%$ ). Fourteen patients $(61 \%)$ had stage IV disease prior to BCBM diagnosis. Median follow-up from the date of brain metastases diagnosis was 20.2 months (range: 5.596.4 months). Twenty-two stereotactic sessions (71\%) occurred within 1 month of the receipt of capecitabine. Stereotactic radiation was delivered concurrently with capecitabine in many of the treatment sessions $(n=15$; $48 \%)$. Stereotactic radiation was delivered before or after capecitabine in $39 \%(n=12)$ and $13 \%(n=4)$ treatment sessions, respectively. In patients not treated concurrently, the median time between receipt of capecitabine and stereotactic radiation was 1.5 months (range: $0.26-$ 5.5 months). Receptor types of patients treated were $30 \%$ $(n=7)$ triple negative, 30\% $(n=7)$ HR+/HER2-, $26 \%$ $(n=6)$ HR+/HER $2+$, and $3(n=13 \%)$ HER $2+$.

Radiation details are described in Table 2. The median PTV of lesions was $0.71 \mathrm{~cm}^{3}$ (range: $0.01-39.1 \mathrm{~cm}^{3}$ ). The median dose of SRS was 21 Gy (range: 15-24 Gy) treated in a single fraction and for lesions treated with FSRT 25 (24-30 Gy) in a median of 5 fractions (range: 3-5). Seven lesions (8\%) were treated post-operatively.

\section{Toxicity assessments and control rates}

No cases of radionecrosis were noted. Radiationrelated toxicity was noted during 5 treatment sessions (16\%) including grade 1-2 nausea/vomiting, headache, and fatigue. Two of these cases were managed with steroids. Prophylactic steroids were prescribed during 11 treatment sessions (35\%) and steroids were continued during radiation for symptoms attributed to BCBM during 7 treatment sessions (23\%). No unexpected scalp toxicities were reported during or after completion of radiation.

Twelve- and 24-month KM LC of treated lesions was 88 and 75\%, while 12- and 24-month DIC was 30 and $15 \%$, respectively (Fig. 1a and b). No differences were noted in LC $(p=0.69)$ and DIC $(p=0.13)$ based on timing of capecitabine and stereotactic radiation. Two patients eventually developed leptomeningeal disease at 6 months and 14.1 months post SRS. Receptor types
Table 1 Patient and Treatment Characteristics

\begin{tabular}{|c|c|c|}
\hline Variable & $\mathrm{n}$ & $\%$ \\
\hline No. of Patients & 23 & \\
\hline Treatment Sessions & 31 & \\
\hline No. of Lesions & 90 & \\
\hline \multicolumn{3}{|l|}{ F/U from RT (months) } \\
\hline Median (range) & $9.2(1.9-94.1)$ & \\
\hline \multicolumn{3}{|c|}{ F/U from Brain Metastases Diagnosis (months) } \\
\hline Median (range) & $20.2(5.5-96.4)$ & \\
\hline \multicolumn{3}{|l|}{ Age at time of RT } \\
\hline Median (range) & $56(40-75)$ & \\
\hline \multicolumn{3}{|l|}{ KPS } \\
\hline 100 & 7 & $30 \%$ \\
\hline 90 & 8 & $35 \%$ \\
\hline 80 & 7 & $30 \%$ \\
\hline 60 & 1 & $4 \%$ \\
\hline \multicolumn{3}{|c|}{ Lesions Treated Per Patient } \\
\hline Median (range) & $3(1-12)$ & \\
\hline \multicolumn{3}{|l|}{ Receptor Status } \\
\hline HR+/HER2- & 7 & $30 \%$ \\
\hline HR- /HER2+ & 3 & $13 \%$ \\
\hline $\mathrm{HR}+/ \mathrm{HER} 2+$ & 6 & $26 \%$ \\
\hline HR-/HER2- & 7 & $30 \%$ \\
\hline \multicolumn{3}{|c|}{ RT in Relation to Capecitabine } \\
\hline Before & 12 & $39 \%$ \\
\hline After & 4 & $13 \%$ \\
\hline Concurrent & 15 & $48 \%$ \\
\hline
\end{tabular}

Interval Between Capecitabine and RT (months)

Median (range) $\quad 1.5(0.26-5.5)$

Concurrent Therapy with Capecitabine

$\begin{array}{lll}\text { None } & 7 & 30 \%\end{array}$

Additional Chemotherapy $\quad 8 \quad 35 \%$

\begin{tabular}{ll} 
Trastuzumab & 2 \\
\hline
\end{tabular}

Trastuzumab + Chemotherapy $\quad 2 \quad 9 \%$

Trastuzumab + TKl $20 \%$

Pembrolizumab $\quad 1 \%$

TKI $1 \%$

Abbreviations: F/U follow-up, $R T$ radiation therapy, KPS Karnofsky performance status, TKI tyrosine kinase inhibitor

were HR+/HER2- and HR+/HER2+, respectively. From the date of stereotactic radiation, median OS was 12 months (95\% CI 7-17 months), and 12- and 24-month OS were 46 and 22\% (Fig. 2). From the date of brain metastasis diagnosis, median OS was 25 months (95\% CI 15.3-46.6 months), and 12- and 24-month OS were 82 and $64 \%$, respectively. 
Table 2 Radiation Treatment Details

\begin{tabular}{|c|c|c|}
\hline Variable & $\mathbf{n}$ & $\%$ \\
\hline \multicolumn{3}{|l|}{ Technique } \\
\hline SRS & 80 & $89 \%$ \\
\hline FSRT & 10 & $11 \%$ \\
\hline \multicolumn{3}{|l|}{ SRS Dose (Gy) } \\
\hline Median (range) & $21(15-24)$ & \\
\hline \multicolumn{3}{|l|}{ FSRT Dose (Gy) } \\
\hline Median (range) & $25(24-30)$ & \\
\hline Fractions & $5(3-5)$ & \\
\hline Postoperative Cavity & 7 & $8 \%$ \\
\hline \multicolumn{3}{|l|}{ PTV $\left(\mathrm{cm}^{3}\right)$} \\
\hline Median (range) & $0.71(0.012-39.1)$ & \\
\hline
\end{tabular}

Abbreviations: PTV Planning target volume, SRS Stereotactic radiosurgery, FSRT Fractionated stereotactic radiotherapy

\section{Discussion}

In this manuscript, we report our experience in the management of BCBM treated with stereotactic radiation and capecitabine. We find no increase in rates of radionecrosis, skin reactions, or other unexpected neurologic toxicities in our cohort with long-term follow-up. In addition, we note local control rates to be high while distant control remains poor consistent with experiences with stereotactic radiation alone.

Capecitabine is activated initially through hepatic metabolism and finally to 5-FU at the level of the cancer cell through the action of thymidine phosphorylase, also known as platelet-derived growth factor, which is expressed at higher levels in cancer cells than in the surrounding normal tissues [16, 17]. Radiation upregulates expression levels of thymidine phosphorylase, thus acting as a greater-than-additive interaction between radiation and capecitabine and making capecitabine a potent radiosensitizer [18]. Capecitabine and 5-FU are particularly utilized in the management of gastrointestinal malignancies [9-11] but synergistic effects with radiotherapy have also been demonstrated in the management of cervical and head and neck cancers [19, 20]. Thus, concurrent administration of capecitabine with radiation therapy should proceed with caution, particularly with high dose radiation therapy surrounding critical structures.

Capecitabine is known to have uptake in BCBM. In a study of eight surgically resected BCBM in which capecitabine was administered hours before surgical resection, measurable drug levels of capecitabine and metabolites, 5 -deoxy-5-fluorocytidine, 5'-deoxy-5-fluorouridine, and 5-fluorouracil, were detected in all resected samples [5]. Capecitabine has also been studied alongside HER TKIs neratinib and lapatinib demonstrating CNS activity $[6,7]$. In addition, the recently reported HER2CLIMB study combined capecitabine with the oral TKI tucatinib and trastuzumab [21]. Among patients with brain metastases, progression-free survival (PFS) at 1 year was $25 \%$ in the tucatinib-combination group and $0 \%$ in the placebo-combination group with a 2.2 month PFS improvement.

Multiple studies have shown stereotactic radiation alone to be well tolerated. The incidence of late toxicity following radiosurgery has been reported to be $4 \%$ [22]. In RTOG 9005, following single fraction radiosurgery, the rates of radiation necrosis in surgical pathology of previously irradiated tissue were 8 and $11 \%$ at 12 and 24 months, respectively [12]. Symptomatic radionecrosis has been reported to be $10 \%$ using radiographic criteria

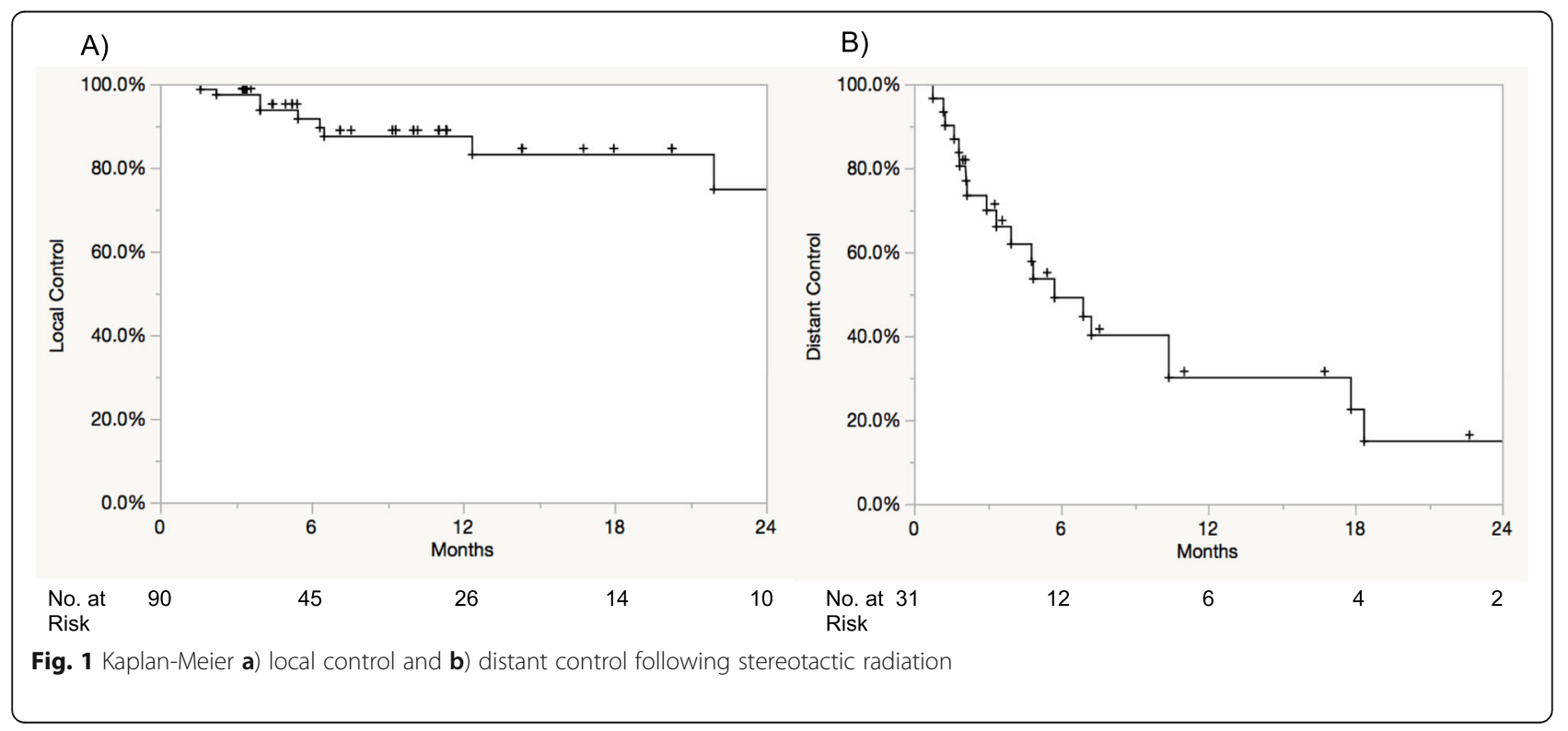




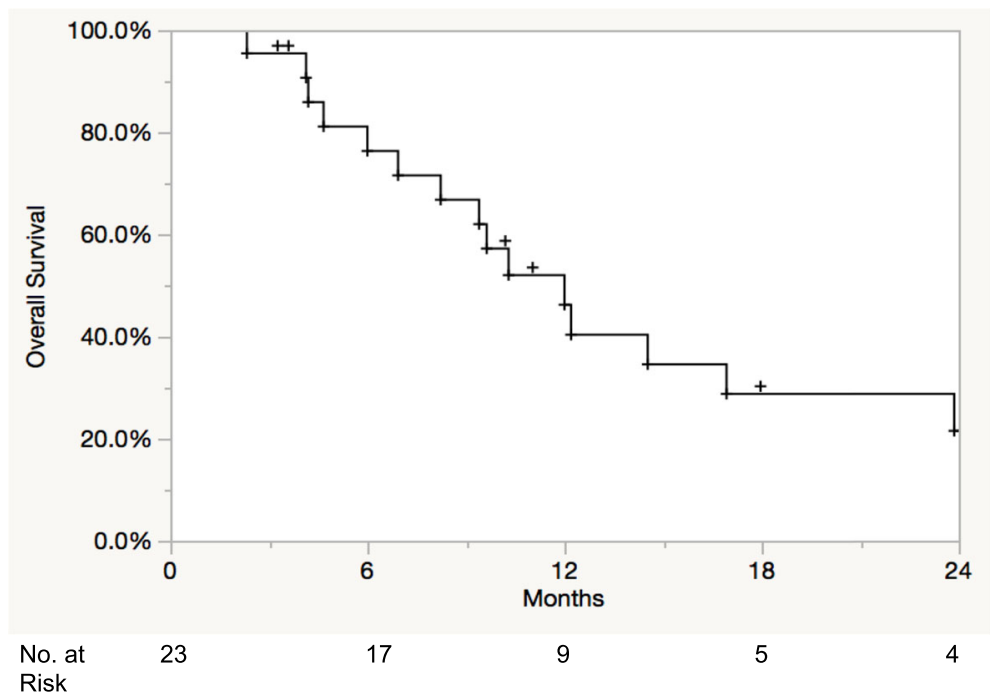

Fig. 2 Kaplan-Meier overall survival following stereotactic radiation

[23]. Concurrent administration of certain systemic agents may increase the risk of radionecrosis following radiosurgery. The administration of concurrent immune checkpoint inhibitors with stereotactic radiation in melanoma, non-small cell lung cancer, and renal cell carcinoma brain metastases has been reported to potentially increase the risk of radionecrosis [24]; however, the rate of radionecrosis was not increased in prospective trials and retrospective series [25-28]. There is also not clear consensus on whether concurrent BRAF inhibition with SRS increases the risk of radionecrosis $[29,30]$ in melanoma brain metastases. In our series with approximately half of BCBM treated with concurrent capecitabine, we did not note any cases of radionecrosis.

Studies have shown that delivery of radiation therapy can facilitate the entry of agents into the blood-tumor barrier in the brain [31-33]. A study from Cao et al. revealed gadolinium diethylenetriaminepentaacetic acid uptake index was highest in the 30 days following whole brain radiation therapy (WBRT) [31]. In addition, the uptake index was higher across the blood-tumor barrier than the blood-brain barrier. Teng et al. analyzed 30 patients with 64 brain metastases treated with either WBRT or SRS, and similarly, 2 to 4 weeks posttreatment there was an increase in permeability for lesions with low permeability at baseline [33]. Administering capecitabine in the window following radiation may increase potential synergy. In a case series of five patients administered WBRT with capecitabine for $\mathrm{BCBM}$, a complete response was noted in 1 patient and partial responses in 2 with grade 1 headaches and nausea reported in two patients each [34].

In this first reported series of capecitabine with stereotactic radiation, intracranial toxicities were similar to those expected with stereotactic radiation alone, including grade 1-2 headaches, fatigue, and nausea/vomiting noted during $15 \%$ of treatment sessions. No cases of radionecrosis were noted. Potential uptake of capecitabine following stereotactic radiation did not appear to increase the risk of toxicity. In addition, local control appears to be within the range of previously reported series, thus further data is needed to support a synergistic effect. However, distant failure continued to be a concern in our series with a poor 12-month distant control rate of $30 \%$.

There are several important limitations to the present study, including its retrospective nature and the heterogeneity of the patient cohort. The small sample size and limited follow up due to the protracted survival of patients with $\mathrm{BCBM}$ limits our conclusions concerning the risk of radionecrosis.

\section{Conclusions}

In conclusion, we note the receipt of capecitabine along with stereotactic radiation to be well tolerated without a side effect profile that appeared to be worse than stereotactic radiation alone. Although local control appears similar to previously reported series, distant control remains poor and warrants further study into novel combinations of systemic therapy along with radiotherapy to improve intracranial progression.

\section{Abbreviations}

BCBM: Breast cancer brain metastases; 5-FU: 5-flourouracil; BBB: Blood-brainbarrier; TKI: Tyrosine kinase inhibitor; CNS: Central nervous system; OS: Overall survival; SRS: Stereotactic radiosurgery; FSRT: Fractionated stereotactic radiotherapy; MRI: Magnetic resonance imaging; CT: Computed tomography; GTV: Gross tumor volume; PTV: Planning target volume; IMRT: Intensity modulated radiotherapy; LC: Local brain metastases control; DIC: Distant intracranial control; KM: Kaplan-Meier; WBRT: Whole brain radiation therapy 


\section{Acknowledgements}

The present study has been presented in part via abstract presentation at the 2020 American Society for Radiation Oncology conference [14].

\section{Authors' contributions}

K.A. and M.M. designed the study and prepared the manuscript. A.N., C.T., C.W., and M.M. contributed to data collection. S.K. provided reviews of the follow up imaging scans for each patient. K.A. performed the statistical analysis. K.A., M.M., H.Y., T.R., N.F., and D.O. contributed to data analysis and interpretation. A.E., H.Y., D.O., T.R., J.L., M.V., P.F., B.C., H.S., and H.H. assisted with data analysis, data interpretation, manuscript editing, and review. All authors have read and approved the manuscript.

\section{Funding}

This research did not receive any specific grant from funding agencies in the public, commercial, or not-for-profit sectors.

\section{Availability of data and materials}

The datasets used and/or analysed during the current study are available from the corresponding author on reasonable request.

\section{Declarations}

\section{Ethics approval and consent to participate}

The University of South Florida Institutional Review Board (ID Pro00023399) approved the present study. The need for consent to participate was waived by the University of South Florida Institutional Review Board, as the present study was a retrospective protocol that utilized anonymized data. Permission to access the data was approved by the University of South Florida Institutional Review Board.

\section{Consent for publication}

Not applicable.

\section{Competing interests}

Hyo S. Han declares that she has received a speaker's honorarium from Lilly Pharmaceuticals, research funding from Abbvie, Tesaro, Taplmmune, Novartis, Bristol-Myers Squibb, Pfizer, SeattleGenetics, Prescient, Horizon, and Karyopharm. Peter A. Forsyth has received research funding from Pfizer and Celgene and is on the advisory boards of Novocure, BTG, Inovio, AbbVie, Ziopharm, Tocagen, and Pfizer. Kamran A. Ahmed has received research funding from Bristol-Myers Squibb and Genentech. Michael A. Vogelbaum has indirect equity and royalty interests in Infuseon Therapeutics, Inc. and has received honoraria from Tocagen, Inc. and Celgene. Hatem Soliman serves as a consultant for Astrazeneca, Celgene, Novartis, PUMA, and Eisai. Brian J Czerniecki has intellectual property on a HER2 dendritic cell vaccine. Hsiang-Hsuan Michael Yu has received spearker's honoraria from BrainLab and is on the advisory boards of Novocure and Abbvie.

\section{Author details}

${ }^{1}$ Department of Radiation Oncology, H. Lee Moffitt Cancer Center and Research Institute, 12902 Magnolia Dr, Tampa, FL 33612, USA. ${ }^{2}$ Morsani College of Medicine, University of South Florida, Tampa, FL 33612, USA. ${ }^{3}$ Department of Radiology, H. Lee Moffitt Cancer Center and Research Institute, Tampa, FL 33612, USA. ${ }^{4}$ Department of Neuro Oncology, H. Lee Moffitt Cancer Center and Research Institute, Tampa, FL 33612, USA. ${ }^{5}$ Department of Breast Oncology, H. Lee Moffitt Cancer Center and Research Institute, Tampa, FL 33612, USA.

\section{Received: 8 March 2021 Accepted: 28 April 2021}

\section{Published online: 15 May 2021}

\section{References}

1. Mills MN, Figura NB, Arrington JA, Yu HM, Etame AB, Vogelbaum MA, et al. Management of brain metastases in breast cancer: a review of current practices and emerging treatments. Breast Cancer Res Treat. 2020;180(2): 279-300. https://doi.org/10.1007/s10549-020-05552-2.

2. Gabos Z, Sinha R, Hanson J, Chauhan N, Hugh J, Mackey JR, et al. Prognostic significance of human epidermal growth factor receptor positivity for the development of brain metastasis after newly diagnosed breast cancer. J Clin Oncol. 2006;24(36):5658-63. https://doi.org/10.1200/ JCO.2006.07.0250.

3. Heitz F, Harter P, Lueck HJ, Fissler-Eckhoff A, Lorenz-Salehi F, Scheil-Bertram $\mathrm{S}$, et al. Triple-negative and HER2-overexpressing breast cancers exhibit an elevated risk and an earlier occurrence of cerebral metastases. Eur J Cancer. 2009;45(16):2792-8. https://doi.org/10.1016/j.ejca.2009.06.027.

4. Hicks DG, Short SM, Prescott NL, Tarr SM, Coleman KA, Yoder BJ, et al. Breast cancers with brain metastases are more likely to be estrogen receptor negative, express the basal cytokeratin CK5/6, and overexpress HER2 or EGFR. Am J Surg Pathol. 2006;30(9):1097-104. https://doi.org/10.1097/01.pas. 0000213306.05811.b9.

5. Morikawa A, Peereboom DM, Thorsheim HR, Samala R, Balyan R, Murphy CG, et al. Capecitabine and lapatinib uptake in surgically resected brain metastases from metastatic breast cancer patients: a prospective study. Neuro-Oncology. 2015;17(2):289-95. https://doi.org/10.1093/neuonc/nou141.

6. Bachelot T, Romieu G, Campone M, Dieras V, Cropet C, Dalenc F, et al. Lapatinib plus capecitabine in patients with previously untreated brain metastases from HER2-positive metastatic breast cancer (LANDSCAPE): a single-group phase 2 study. Lancet Oncol. 2013;14(1):64-71. https://doi. org/10.1016/S1470-2045(12)70432-1.

7. Freedman RA, Gelman RS, Anders CK, Melisko ME, Parsons HA, Cropp AM, et al. TBCRC 022: a phase II trial of Neratinib and Capecitabine for patients with human epidermal growth factor receptor 2-positive breast Cancer and brain metastases. J Clin Oncol. 2019;37(13):1081-9. https://doi.org/10.1200/ JCO.18.01511.

8. Masuda N, Lee SJ, Ohtani S, Im YH, Lee ES, Yokota I, et al. Adjuvant Capecitabine for breast Cancer after preoperative chemotherapy. N Engl J Med. 2017:376(22):2147-59. https://doi.org/10.1056/NEJMoa1612645.

9. Regine WF, Winter KA, Abrams R, Safran H, Hoffman JP, Konski A, et al. Fluorouracil-based chemoradiation with either gemcitabine or fluorouracil chemotherapy after resection of pancreatic adenocarcinoma: 5-year analysis of the U.S. intergroup/RTOG 9704 phase III trial. Ann Surg Oncol. 2011;18(5): 1319-26. https://doi.org/10.1245/s10434-011-1630-6.

10. Allegra CJ, Yothers G, O'Connell MJ, Beart RW, Wozniak TF, Pitot HC, et al. Neoadjuvant 5-FU or Capecitabine Plus Radiation With or Without Oxaliplatin in Rectal Cancer Patients: A Phase III Randomized Clinical Trial. J Natl Cancer Inst. 2015;107(11). PMID: 26374429.

11. Kachnic LA, Winter K, Myerson RJ, Goodyear MD, Willins J, Esthappan J, et al. RTOG 0529: a phase 2 evaluation of dose-painted intensity modulated radiation therapy in combination with 5-fluorouracil and mitomycin- $\mathrm{C}$ for the reduction of acute morbidity in carcinoma of the anal canal. Int J Radiat Oncol Biol Phys. 2013;86(1):27-33. https://doi. org/10.1016/j.jijrobp.2012.09.023.

12. Shaw E, Scott C, Souhami L, Dinapoli R, Kline R, Loeffler J, et al. Single dose radiosurgical treatment of recurrent previously irradiated primary brain tumors and brain metastases: final report of RTOG protocol 90-05. Int J Radiat Oncol Biol Phys. 2000;47(2):291-8. https://doi.org/10.1016/S0360-301 6(99)00507-6.

13. Mills MN, Walker $C$, Thawani $C$, Naz A, Figura NB, Kushchayev $S$, et al. Trastuzumab Emtansine (T-DM1) and stereotactic radiation in the management of HER2+ breast cancer brain metastases. BMC Cancer. 2021; 21(1):223. https://doi.org/10.1186/s12885-021-07971-w.

14. Mills MN, Naz A, Thawani C, Walker C, Figura NB, Forsyth $P$, et al. Clinical outcomes of breast Cancer brain metastases treated with stereotactic radiation and Capecitabine. IJROBP. 2020;108(3):E685-6.

15. Lin NU, Lee EQ, Aoyama H, Barani IJ, Barboriak DP, Baumert BG, et al. Response assessment criteria for brain metastases: proposal from the RANO group. Lancet Oncol. 2015;16(6):e270-8. https://doi.org/10.1016/S1470-204 5(15)70057-4.

16. Schuller J, Cassidy J, Dumont E, Roos B, Durston S, Banken L, et al. Preferential activation of capecitabine in tumor following oral administration to colorectal cancer patients. Cancer Chemother Pharmacol. 2000;45(4):291-7. https://doi.org/10.1007/s002800050043.

17. Schilsky RL. Pharmacology and clinical status of capecitabine. Oncology (Williston Park, NY). 2000;14(9):1297-306 discussion 1309-1211.

18. Sawada N, Ishikawa T, Sekiguchi F, Tanaka $Y$, Ishitsuka H. X-ray irradiation induces thymidine phosphorylase and enhances the efficacy of capecitabine (Xeloda) in human cancer xenografts. Clin Cancer Res. 1999; 5(10):2948-53.

19. Whitney CW, Sause W, Bundy BN, Malfetano JH, Hannigan EV, Fowler WC Jr, et al. Randomized comparison of fluorouracil plus cisplatin versus 
hydroxyurea as an adjunct to radiation therapy in stage IIB-IVA carcinoma of the cervix with negative Para-aortic lymph nodes: a gynecologic oncology group and southwest oncology group study. J Clin Oncol. 1999;17(5):133948. https://doi.org/10.1200/JCO.1999.17.5.1339.

20. Adelstein DJ, Li Y, Adams GL, Wagner H Jr, Kish JA, Ensley JF, et al. An intergroup phase III comparison of standard radiation therapy and two schedules of concurrent chemoradiotherapy in patients with unresectable squamous cell head and neck cancer. J Clin Oncol. 2003;21(1):92-8. https:// doi.org/10.1200/JCO.2003.01.008.

21. Murthy RK, Loi S, Okines A, Paplomata E, Hamilton E, Hurvitz SA, et al. Tucatinib, Trastuzumab, and Capecitabine for HER2-positive metastatic breast Cancer. N Engl J Med. 2020;382(7):597-609. https://doi.org/10.1056/ NEJMoa1914609.

22. Aoyama H, Shirato H, Tago M, Nakagawa K, Toyoda T, Hatano K, et al. Stereotactic radiosurgery plus whole-brain radiation therapy vs stereotactic radiosurgery alone for treatment of brain metastases: a randomized controlled trial. JAMA. 2006;295(21):2483-91. https://doi.org/10.1001/jama.2 95.21.2483.

23. Minniti G, Clarke E, Lanzetta G, Osti MF, Trasimeni G, Bozzao A, et al. Stereotactic radiosurgery for brain metastases: analysis of outcome and risk of brain radionecrosis. Radiat Oncol. 2011;6:48.

24. Martin AM, Cagney DN, Catalano PJ, Alexander BM, Redig AJ, Schoenfeld JD, et al. Immunotherapy and symptomatic radiation necrosis in patients with brain metastases treated with stereotactic radiation. JAMA Oncol. 2018;4(8): 1123-4. https://doi.org/10.1001/jamaoncol.2017.3993.

25. Ahmed KA, Abuodeh YA, Echevarria MI, Arrington JA, Stallworth DG, Hogue C, et al. Clinical outcomes of melanoma brain metastases treated with stereotactic radiosurgery and anti-PD-1 therapy, anti-CTLA-4 therapy, BRAF/ MEK inhibitors, BRAF inhibitor, or conventional chemotherapy. Ann Oncol. 2016;27(12):2288-94. https://doi.org/10.1093/annonc/mdw417.

26. Ahmed KA, Kim S, Arrington J, Naghavi AO, Dilling TJ, Creelan BC, et al. Outcomes targeting the PD-1/PD-L1 axis in conjunction with stereotactic radiation for patients with non-small cell lung cancer brain metastases. J Neuro-Oncol. 2017;133(2):331-8. https://doi.org/10.1007/s11060-017-2437-5.

27. Williams NL, Wuthrick EJ, Kim H, Palmer JD, Garg S, Eldredge-Hindy H, et al. Phase 1 study of Ipilimumab combined with whole brain radiation therapy or radiosurgery for melanoma patients with brain metastases. Int J Radiat Oncol Biol Phys. 2017;99(1):22-30. https://doi. org/10.1016/j.jijobp.2017.05.028.

28. Hubbeling HG, Schapira EF, Horick NK, Goodwin KEH, Lin JJ, Oh KS, et al. Safety of combined PD-1 pathway inhibition and intracranial radiation therapy in non-small cell lung Cancer. J Thorac Oncol. 2018;13(4):550-8. https://doi.org/10.1016/j.jtho.2018.01.012.

29. Patel KR, Chowdhary M, Switchenko JM, Kudchadkar R, Lawson DH, Cassidy $\mathrm{RJ}$, et al. BRAF inhibitor and stereotactic radiosurgery is associated with an increased risk of radiation necrosis. Melanoma Res. 2016;26(4):387-94. https://doi.org/10.1097/CMR.0000000000000268.

30. Ahmed KA, Freilich JM, Sloot S, Figura N, Gibney GT, Weber JS, et al. LINACbased stereotactic radiosurgery to the brain with concurrent vemurafenib for melanoma metastases. J Neuro-Oncol. 2015;122(1):121-6. https://doi. org/10.1007/s1 1060-014-1685-x.

31. Cao Y, Tsien Cl, Shen Z, Tatro DS, Ten Haken R, Kessler ML, et al. Use of magnetic resonance imaging to assess blood-brain/blood-glioma barrier opening during conformal radiotherapy. J Clin Oncol. 2005;23(18):4127-36. https://doi.org/10.1200/JCO.2005.07.144.

32. Appelboom G, Detappe A, LoPresti M, Kunjachan S, Mitrasinovic S, Goldman $\mathrm{S}$, et al. Stereotactic modulation of blood-brain barrier permeability to enhance drug delivery. Neuro-oncology. 2016;18(12):1601-9. https://doi. org/10.1093/neuonc/now137.

33. Teng F, Tsien Cl, Lawrence TS, Cao Y. Blood-tumor barrier opening changes in brain metastases from pre to one-month post radiation therapy. Radiother Oncol. 2017;125(1):89-93. https://doi.org/10.1016/j.ra donc.2017.08.006

34. Chargari C, Kirova YM, Dieras V, Castro Pena P, Campana F, Cottu PH, et al. Concurrent capecitabine and whole-brain radiotherapy for treatment of brain metastases in breast cancer patients. J Neuro-Oncol. 2009;93(3):37984. https://doi.org/10.1007/s11060-008-9791-2.

\section{Publisher's Note}

Springer Nature remains neutral with regard to jurisdictional claims in published maps and institutional affiliations.

Ready to submit your research? Choose BMC and benefit from:

- fast, convenient online submission

- thorough peer review by experienced researchers in your field

- rapid publication on acceptance

- support for research data, including large and complex data types

- gold Open Access which fosters wider collaboration and increased citations

- maximum visibility for your research: over $100 \mathrm{M}$ website views per year

At BMC, research is always in progress.

Learn more biomedcentral.com/submissions 